\title{
PROPOSTA DE MODELO PARA OTIMIZAÇÃO DE UM O PROBLEMA DE PRODUÇÃO E DE TRANSPORTES MULTIPRODUTO, MULTIPERÍODO E POR DIFERENTES MEIOS DE TRANSPORTE
}

\author{
Fabire Soares Rezende \\ Instituto Militar de Engenharia \\ Praça General Tibúrcio, 80, Urca, Rio de Janeiro, RJ \\ engfcfabirerezende@gmail.com \\ Orivalde Soares da Silva Júnior \\ Instituto Militar de Engenharia \\ Praça General Tibúrcio, 80, Urca, Rio de Janeiro, RJ \\ orivalde@ime.eb.br \\ RESUMO
}

\begin{abstract}
Este artigo tem por objetivo propor um modelo matemático de programação linear que resolva um problema produção e de transportes com multiproduto, multiperíodo e por diferentes meios de transporte entre as plantas de uma fábrica e seus clientes. Somado a isso, realizar um experimento computacional didático utilizando o software de modelagem AIMMS. Foram criados dados fictícios para testar e validar o modelo. Os resultados encontrados como solução ótima do problema foram analisados e discutidos, incorrendo em conclusões que apontam uma modelagem coerente.
\end{abstract}

Palavra-chave: Problema de transportes; Problema de produção; Multiproduto; Multiperíodo; AIMMS.

ABSTRACT

This paper aims to propose a mathematical model of linear programming that solves a production and transportation problem of multi-product, multi-period and different transportation between plants of a factory and its customers. In addition, we did a didactic computational experiment using AIMMS modeling software. Dummy data was created to test and validate the model. The results found as the optimal solution of the problem were analyzed and discussed, leading to conclusions that point to a coherent modeling.

Keywords: Transportation problem; Production problem; Multi-product; Multiperiod; AIMMS.

\section{Como Citar:}

REZENDE, Fabire Soares; SILVA JÚNIOR, Orivalde Soares da. Proposta de Modelo para Otimização de um Problema de Produção e de Transportes Multiproduto, Multiperíodo e por Diferentes Meios de Transporte. In: SIMPÓSIO DE PESQUISA OPERACIONAL E LOGÍSTICA DA MARINHA, 19., 2019, Rio de Janeiro, RJ. Anais [...]. Rio de Janeiro: Centro de Análises de Sistemas Navais, 2019. 


\section{INTRODUÇÃO}

Este artigo tem como objetivo propor um modelo matemático de programação linear. Foram buscados dados reais, para validação do modelo e estudo de caso, com algumas empresas de do setor de produção e de logística que atuam no Brasil, porém diante da escassez desses dados, bem como da incompatibilidade com o modelo proposto, foi decidido por aplicar o modelo a um caso fictício. Apesar disso, tanto o modelo quanto os dados poderiam ser adequados a situações reais para diversas empresas nacionais e internacionais.

Este trabalho é fruto de uma atividade proposta no primeiro período de mestrado na disciplina Métodos de Otimização I em que o primeiro autor teve como principal pretensão o aprofundamento de seus conhecimentos no campo da programação linear, bem como o aprendizado na utilização do software AIMMS como ferramenta na resolução de problemas dessa área.

O problema base deste artigo é um problema de produção e de transportes com multiproduto, multiperíodo e com possibilidade de distribuição dos produtos entre as origens e os destinos por diferentes meios de transporte. Envolve uma situação em que se tem mais de um produto sendo produzido por plantas distintas de uma fábrica, sendo atrelado, respectivamente, a cada produto e período de tempo de cada planta: custos de produção; custos de estocagem; capacidades de produção; capacidades de estocagem; demandas pelos compradores e custos de transportes por meio de transporte e por destino.

Os custos analisados na função objetivo serão: os custos de produção de multiprodutos em horas normais e em horas extras em multiperíodos de tempo; os custos de armazenamento de multiprodutos em multiperíodos de tempo; e os custos associados aos transportes por diferentes meios, desde os pontos de origem, que são as plantas da fábrica, até os pontos de destino, que são os compradores.

\section{REVISÃO BIBLIOGRÁFICA}

De acordo com Nogueira (2010) o problema de transporte é um tipo de problema de programação linear (PL) e consiste em determinar o menor custo (ou maior lucro) em transportar produtos de várias origens para vários destinos e possui aplicação direta para a logística. No caso deste artigo, busca-se minimizar os custos de produção, estoques e transportes.

Problemas de fluxo multiproduto, conforme Santos e Marujo (2012), são um tipo de problema de redes de transporte em que ocorre um fluxo de diferentes produtos compartilhando um mesmo arco, e estes produtos podem possuir diferentes custos associados ou diferentes restrições que normalmente são complicadores no modelo matemático, podendo torná-los inclusive dependentes, ou seja, fazendo com que eles interajam entre si.

Poldi e Anerales (2010) definem os problemas multiperíodos como sendo aqueles tipicamente associados ao planejamento e programação de empresas que têm um regime de demandas em períodos diversos em um horizonte de planejamento finito. Assim, os objetos ou produtos não utilizados em um período ficam disponíveis no próximo, juntamente com os possíveis novos objetos ou produtos produzidos pela fábrica.

\section{MODELO MATEMÁTICO DO PROBLEMA}

O modelo matemático utilizado para resolver o problema proposto será apresentado a seguir. 
$\mathrm{O}$ índice $p$ representa a planta/origem, com $p \in \mathrm{P}, \mathrm{P}=\{1, \ldots, q\}$, o índice $t$ representa o período, com $t \in \mathrm{T}, \mathrm{T}=\{1, \ldots, m\}$, o índice $i$ representa o produto, $i \in \mathrm{I}, \mathrm{I}=\{1, \ldots, n\}, \mathrm{o}$ índice $j$ representa o comprador/destino, com $j \in \mathrm{J}, \mathrm{J}=\{1, \ldots, o\}$, o índice $m$ representa o meio de transporte, com $m \in \mathrm{M}, \mathrm{M}=\{1, \ldots, r\}$.

Os parâmetros utilizados no modelo são: $a_{p i t}$ que representa o custo de produção na planta/origem $p$ do produto $i$ no período $t$ em horas normais de produção; $b_{\text {pit }}$ representa o custo de produção na planta/origem $p$ do produto $i$ no período $t$ em horas extras; $c_{p i t}$ representa o custo de estocagem na planta/origem $p$ do produto $i$ no período $t ; d_{p i t}$ representa a capacidade máxima de produção na planta/origem $p$ do produto $i$ no período $t$ em horas normais de produção; $e_{p i t}$ representa a capacidade máxima de produção na planta/origem $p$ do produto $i$ no período $t$ em horas extras de produção; $f_{\text {pit }}$ representa a capacidade de estocagem na planta/origem $p$ do produto $i$ no período $t$; $g_{i t j}$ representa a demanda do produto $i$ no período $t$ pelo comprador/destino $j ; h_{\text {pitjm }}$ representa o custo do transporte da planta/origem $p$ do produto $i$ no período $t$ para o comprador/destino $j$ no meio de transporte $m$.

Foram definidas as variáveis de decisão: $X_{p i t}$ que indica a quantidade a ser produzida na planta/origem $p$ do produto $i$ no período $t$ em horas normais de produção; $Y_{p i t}$ indica a quantidade a ser produzido na planta/origem $p$ do produto $i$ no período $t$ em horas extras de produção; $W_{p i t}$ indica a quantidade a ser estocada na planta/origem $p$ do produto $i$ no período $t ; V_{\text {pitjm }}$ indica a quantidade a ser enviada da planta/origem $p$ do produto $i$ no período $t$ para o comprador/destino $j$ no meio de transporte $m$. As expressões de (1) a (7) representam o modelo matemático de programação linear proposto.

$$
\begin{aligned}
& \operatorname{Min}_{x, y, w, y} Z=\sum_{p=1}^{q} \sum_{i=1}^{n} \sum_{t=1}^{m}\left(X_{p i t} \dot{i} \dot{i} i a_{p i t}+Y_{p i t} b_{p i t}+W_{p i t} c_{p i t}\right)+\sum_{p=1}^{q} \sum_{i=1}^{n} \sum_{t=1}^{m} \sum_{j=1}^{o} \sum_{m=1}^{r}\left(V_{p i t j m} \dot{i} \dot{i} \dot{i} \dot{ } h_{p i}\right. \\
& \text { s.a. } \\
& X_{p i t} \leq d_{p i t} ; \forall p \in P, \forall i \in I, \forall t \in T \\
& Y_{p i t} \leq e_{p i t} ; \forall p \in P, \forall i \in I, \forall t \in T \\
& W_{p i t} \leq f_{p i t} ; \forall p \in P, \forall i \in I, \forall t \in T \\
& W_{p i t}=X_{p i t}+Y Y_{p i t}+W_{p i t-1}-\sum_{j \in J} \sum_{m \in M} V_{p i t j m} ; \forall p \in P, \forall i \in I, t \in T \\
& \sum_{p \in P} \sum_{m \in M} V_{p i t j} \geq g_{i t j} ; \forall i \in I, \forall t \in T, \forall j \in J \\
& X_{p i t}, Y_{p i t}, W_{p i t}, V_{p i t j m} \geq 0 ; \forall p \in P, \forall i \in I, \forall t \in T, \forall j C, \forall m \in M
\end{aligned}
$$

A expressão (1) é a função objetivo que minimiza os somatórios das variáveis de decisão multiplicadas pelos custos unitários respectivos. As restrições (2) garantem que a quantidade produzida na planta $p$ de produtos $i$ no período $t$ não exceda a capacidade máxima de produção em horas normais. As restrições (3) garantem que a quantidade produzida na planta $p$ de produtos $i$ no período $t$ não exceda a capacidade máxima de produção em horas extras. As restrições (4) garantem que o nível de estocagem na planta $p$ do produto $i$ no período $t$ não exceda a capacidade de estocagem. As restrições (5) são restrições de equilíbrio entre os períodos. As restrições (6) garantem o atendimento da demanda de produtos $i$ no período $t$ pelo comprador $j$. As restrições (7) definem os domínios das variáveis de decisão como valores positivos.

\section{DADOS DO PROBLEMA}

Os dados do problema que compõem as matrizes dos índices e dos parâmetros são fictícios, mas possuem o objetivo de validar o modelo. Os conjuntos foram preenchidos com 
uma fábrica com 2 plantas de produção, 4 períodos de tempo que representam as semanas de um mês, 2 produtos, 4 compradores e 3 meios de transporte diferentes.

Para os parâmetros foram considerados valores fictícios, porém que pudessem exemplificar uma situação real, de modo que os custos sejam diferentes entre as plantas, os produtos, os períodos, os compradores e os meios de transporte. Além disso, com capacidades máximas e demandas também distintas em relação aos índices. Todos os valores adotados para dos parâmetros são apresentados no Apêndice I.

\section{RESULTADOS}

O modelo matemático de programação linear proposto na seção 3 foi modelado no software AIMMS. Após isso, os dados fictícios, apresentados nas Tabelas de 1 a 18 do Apêndice I, foram preenchidos como entrada para fins de cálculo da solução ótima do problema. O software rodou o modelo com os dados e obteve: 97 restrições; 241 variáveis (sendo 240 variáveis inteiras); por meio do pacote Solver CPLEX 12.8. Foram necessárias 32 iterações e solução ótima para a função objetivo de $\mathrm{R} \$ 694.130,00$, com tempo de solução de 0,06 segundos. Os valores ótimos calculados para as variáveis de decisão são apresentados a seguir nas Tabelas de 1 a 8 .

Tabela 1: Valores ótimos de quanto produzir na planta/origem 1 em horas normais de produção $\left(X_{p i t}\right)$

\begin{tabular}{c|c|c|c}
\hline \multicolumn{4}{c}{ Planta/Origem 1 - Valores ótimos de $\boldsymbol{X}_{\text {pit }}$} \\
\hline Produtos & Períodos & Quantidade & Unidades \\
\hline \multirow{4}{*}{ Produto 1 } & Período 1 & 1000 & Un \\
\cline { 2 - 4 } & Período 2 & 1000 & Un \\
\cline { 2 - 4 } & Período 3 & 1500 & Un \\
\cline { 2 - 4 } & Período 4 & 1500 & Un \\
\hline \multirow{4}{*}{ Produto 2 } & Período 1 & 2000 & Un \\
\cline { 2 - 4 } & Período 2 & 2500 & Un \\
\cline { 2 - 4 } & Período 3 & 3000 & Un \\
\cline { 2 - 4 } & Período 4 & 2500 & Un \\
\cline { 2 - 4 }
\end{tabular}

Tabela 2: Valores ótimos de quanto produzir na planta/origem 2 em horas normais de produção $\left(X_{p i t}\right)$

Planta/Origem 2 - Valores ótimos de $X_{\text {pit }}$

\begin{tabular}{c|c|c|c}
\hline Produtos & Períodos & Quantidade & Unidades \\
\hline \multirow{4}{*}{ Produto 1 } & Período 1 & 2000 & Un \\
\cline { 2 - 4 } & Período 2 & 2500 & Un \\
\cline { 2 - 4 } & Período 3 & 2000 & Un \\
\cline { 2 - 4 } & Período 4 & 1500 & Un \\
\hline \multirow{4}{*}{ Produto 2 } & Período 1 & 1000 & Un \\
\cline { 2 - 4 } & Período 2 & 1500 & Un \\
\cline { 2 - 4 } & Período 3 & 1700 & Un \\
\cline { 2 - 4 } & Período 4 & 3000 & Un \\
\cline { 2 - 4 }
\end{tabular}

Tabela 3: Valores ótimos de quanto produzi na planta/origem 1 em horas extras de produção ( $\left.Y_{\text {pit}}\right)$

Planta/Origem 1 - Valores ótimos de $Y_{\text {pit }}$

\begin{tabular}{c|c|c|c}
\hline Produtos & Períodos & Quantidade & Unidades \\
\hline \multirow{4}{*}{ Produto 1 } & Período 1 & 3000 & Un \\
\cline { 2 - 4 } & Período 2 & 2500 & Un \\
\cline { 2 - 4 } & Período 3 & 450 & Un \\
\cline { 2 - 4 } & Período 4 & 2500 & Un \\
\hline \multirow{4}{*}{ Produto 2 } & Período 1 & 2500 & Un \\
\cline { 2 - 4 } & Período 2 & 2000 & Un \\
\cline { 2 - 4 } & Período 3 & 0 & Un \\
\cline { 2 - 4 } & Período 4 & 0 & Un \\
\cline { 2 - 4 }
\end{tabular}


Tabela 4: Valores ótimos de quanto produzi na planta/origem 2 em horas extras de produção ( $\left.Y_{p i t}\right)$

Planta/Origem 2 - Valores ótimos de $Y_{\text {pit }}$

\begin{tabular}{c|c|c|c}
\hline Produtos & Períodos & Quantidade & Unidades \\
\hline \multirow{4}{*}{ Produto 1 } & Período 1 & 1250 & $\mathrm{Un}$ \\
\cline { 2 - 4 } & Período 2 & 0 & $\mathrm{Un}$ \\
\cline { 2 - 4 } & Período 3 & 4000 & $\mathrm{Un}$ \\
\cline { 2 - 4 } & Período 4 & 0 & $\mathrm{Un}$ \\
\hline \multirow{4}{*}{ Produto 2 } & Período 1 & 1000 & $\mathrm{Un}$ \\
\cline { 2 - 4 } & Período 2 & 300 & $\mathrm{Un}$ \\
\cline { 2 - 4 } & Período 3 & 0 & $\mathrm{Un}$ \\
\cline { 2 - 4 } & Período 4 & 500 & $\mathrm{Un}$ \\
\cline { 2 - 4 }
\end{tabular}

Tabela 5: Valores ótimos de nível de estoque na planta/origem $1\left(W_{p i t}\right)$

\begin{tabular}{c|c|c|c}
\hline \multicolumn{4}{c}{ Planta/Origem 1 - Valores ótimos de $\boldsymbol{W}_{\text {pit }}$} \\
\hline Produtos & Períodos & Quantidade & Unidades \\
\hline \multirow{4}{*}{ Produto 1 } & Período 1 & 100 & Un \\
\cline { 2 - 4 } & Período 2 & 0 & Un \\
\cline { 2 - 4 } & Período 3 & 0 & Un \\
\cline { 2 - 4 } & Período 4 & 0 & Un \\
\hline \multirow{4}{*}{ Produto 2 } & Período 1 & 0 & Un \\
\cline { 2 - 4 } & Período 2 & 0 & Un \\
\cline { 2 - 4 } & Período 3 & 2500 & Un \\
\cline { 2 - 4 } & Período 4 & 0 & Un \\
\cline { 2 - 4 }
\end{tabular}

Tabela 6: Valores ótimos de nível de estoque na planta/origem $2\left(W_{p i t}\right)$

Planta/Origem 2 - Valores ótimos de $W_{\text {pit }}$

\begin{tabular}{c|c|c|c}
\hline Produtos & Períodos & Quantidade & Unidades \\
\hline \multirow{4}{*}{ Produto 1 } & Período 1 & 1000 & Un \\
\cline { 2 - 4 } & Período 2 & 0 & Un \\
\cline { 2 - 4 } & Período 3 & 800 & Un \\
\cline { 2 - 4 } & Período 4 & 0 & Un \\
\hline \multirow{4}{*}{ Produto 2 } & Período 1 & 0 & Un \\
\cline { 2 - 4 } & Período 2 & 0 & Un \\
\cline { 2 - 4 } & Período 3 & 700 & Un \\
\cline { 2 - 4 } & Período 4 & 0 & Un \\
\cline { 2 - 4 }
\end{tabular}

Tabela 7: Valores ótimos de quanto enviar da planta/origem $1\left(V_{\text {pitjm }}\right)$

\begin{tabular}{|c|c|c|c|c|c|}
\hline \multicolumn{6}{|c|}{ Planta/Origem 1 - Valores ótimos de $V_{\text {pitim }}$} \\
\hline Produtos & Períodos & Comprador & Meio de Transporte & Quantidade & Unidades \\
\hline \multirow{8}{*}{ Produto 1} & Período 1 & Comprador/Destino 1 & Meio de Transporte 1 & 3900 & Un \\
\hline & \multirow{2}{*}{ Período 2} & Comprador/Destino 1 & \multirow{2}{*}{ Meio de Transporte 1} & 3500 & Un \\
\hline & & Comprador/Destino 4 & & 100 & Un \\
\hline & \multirow{2}{*}{ Período 3} & Comprador/Destino 1 & \multirow{2}{*}{ Meio de Transporte 2} & 1800 & Un \\
\hline & & Comprador/Destino 4 & & 150 & Un \\
\hline & \multirow{3}{*}{ Período 4} & Comprador/Destino 1 & Meio de Transporte 3 & 3700 & Un \\
\hline & & Comprador/Destino 2 & Meio de Transporte 2 & 100 & Un \\
\hline & & Comprador/Destino 4 & Meio de Transporte 3 & 200 & Un \\
\hline \multirow{10}{*}{ Produto 2} & \multirow{3}{*}{ Período 1} & Comprador/Destino 1 & \multirow{3}{*}{ Meio de Transporte 3} & 4100 & Un \\
\hline & & Comprador/Destino 3 & & 100 & Un \\
\hline & & Comprador/Destino 4 & & 300 & Un \\
\hline & \multirow{3}{*}{ Período 2} & Comprador/Destino 1 & \multirow{3}{*}{ Meio de Transporte 3} & 3400 & Un \\
\hline & & Comprador/Destino 2 & & 1000 & Un \\
\hline & & Comprador/Destino 3 & & 100 & Un \\
\hline & Período 3 & Comprador/Destino 2 & Meio de Transporte 1 & 500 & Un \\
\hline & \multirow{3}{*}{ Período 4} & Comprador/Destino 1 & Meio de Transporte 2 & 2900 & Un \\
\hline & & Comprador/Destino 2 & Meio de Transporte 3 & 2000 & Un \\
\hline & & Comprador/Destino 4 & Meio de Transporte 1 & 100 & Un \\
\hline
\end{tabular}


Tabela 8: Valores ótimos de quanto enviar da planta/origem $2\left(V_{\text {pitjm }}\right)$

Planta/Origem 2 - Valores ótimos de $V_{\text {pitjm }}$

\begin{tabular}{|c|c|c|c|c|c|}
\hline Produtos & Períodos & Comprador & Meio de Transporte & Quantidade & Unidades \\
\hline \multirow{12}{*}{ Produto 1} & \multirow{4}{*}{ Período 1} & Comprador/Destino 1 & \multirow{2}{*}{ Meio de Transporte 3} & 1100 & Un \\
\hline & & Comprador/Destino 2 & & 1000 & Un \\
\hline & & Comprador/Destino 3 & Meio de Transporte 1 & 100 & Un \\
\hline & & Comprador/Destino 4 & Meio de Transporte 3 & 50 & Un \\
\hline & \multirow{3}{*}{ Período 2} & Comprador/Destino 1 & \multirow{3}{*}{ Meio de Transporte 3} & 500 & Un \\
\hline & & Comprador/Destino 2 & & 2500 & Un \\
\hline & & Comprador/Destino 3 & & 500 & Un \\
\hline & \multirow{3}{*}{ Período 3} & Comprador/Destino 1 & \multirow{2}{*}{ Meio de Transporte 3} & 1200 & Un \\
\hline & & Comprador/Destino 2 & & 3000 & Un \\
\hline & & Comprador/Destino 3 & Meio de Transporte 2 & 1000 & Un \\
\hline & \multirow{2}{*}{ Período 4} & Comprador/Destino 1 & Meio de Transporte 3 & 1300 & Un \\
\hline & & Comprador/Destino 3 & Meio de Transporte 1 & 1000 & Un \\
\hline \multirow{10}{*}{ Produto 2} & \multirow{2}{*}{ Período 1} & Comprador/Destino 1 & Meio de Transporte 2 & 1900 & Un \\
\hline & & Comprador/Destino 2 & Meio de Transporte 1 & 100 & Un \\
\hline & \multirow{2}{*}{ Período 2} & Comprador/Destino 1 & \multirow{2}{*}{ Meio de Transporte 2} & 1600 & Un \\
\hline & & Comprador/Destino 4 & & 200 & Un \\
\hline & \multirow{4}{*}{ Período 3} & Comprador/Destino 1 & \multirow{2}{*}{ Meio de Transporte 3} & 200 & Un \\
\hline & & Comprador/Destino 2 & & 500 & Un \\
\hline & & Comprador/Destino 3 & Meio de Transporte 1 & 200 & Un \\
\hline & & Comprador/Destino 4 & Meio de Transporte 2 & 100 & Un \\
\hline & \multirow{2}{*}{ Período 4} & Comprador/Destino 1 & Meio de Transporte 1 & 4100 & Un \\
\hline & & Comprador/Destino 3 & Meio de Transporte 2 & 100 & Un \\
\hline
\end{tabular}

\section{CONCLUSÕES}

Analisando-se os resultados obtidos como solução ótima para o problema abordado, destacam-se alguns valores.

Será nula a necessidade de produção em horas extras nas seguintes situações: na planta 1 para o produto 2 nos períodos 3 e 4 ; na planta 2 para o produto 1 nos períodos 2 e 4 ; na planta 2 para o produto 2 no período 3. Nesses casos, serão suficientes as produções em horas normais acrescidas dos estoques.

Para a planta 1 , haverá necessidade de estocagem apenas no período 1 para o produto 1 (100 unidades) e no período 3 para o produto 2 (500 unidades).

Para a planta 2, haverá necessidade de estocagem apenas nos períodos 1 e 3 para o produto 1 (1000 e 800 unidades, respectivamente) e no período 3 para o produto 2 (700 unidades).

Os valores da variável de decisão quantidade a ser enviada ( $\left.V_{\text {pitjm }}\right)$ foram bastante diversificados. Há uma grande variação dentre os meios de transportes a serem utilizados ao longo dos períodos, para cada produto e entre cada planta/origem e comprador/destino, de modo que a opção foi sempre por aquele que proporciona o menor custo de transporte.

Dessa forma, o software AIMMS calculou um custo mínimo ótimo de R\$694.130 em que estão incluídos todos os custos inseridos no modelo matemático de otimização proposto neste trabalho.

Os resultados encontrados são coerentes com os dados lançados e indicam que a modelagem proposta atende ao seu propósito de resolver problemas de transporte com multiproduto, multiperíodo e por diferentes meios de transporte.

\section{REFERÊNCIAS BIBLIOGRÁFICAS}


[1] Goldbarg, M. C. (2005), Otimização Combinatória e Programação Linear: Modelos e Algoritmos, Elsevier Editora Ltda.

[2] Luche, J. R. D., Francisco, A. (2017), Pesquisa operacional - Aula 20 - Modelos Multiperíodos, UNIVESP, Disponível em: <https://www.youtube.com/watch? $\mathrm{v}=\mathrm{gJyF} 6 \mathrm{co} 8 \mathrm{qTY}>$ Acesso em: 08 de abril de 2019.

[3] Nogueira, F. (2010), Problema de Transporte (Redes). UFJF. Disponível em: $<$ http://www.ufjf.br/epd015/files/2010/06/problema_de_transporte.pdf $>$ Acesso em: 27 de abril de 2019.

[4] Poldi, K. C., Arenales, M. N. (2010), O problema de corte de estoque unidimensional multiperíodo. Publicação da Sociedade Brasileira de Pesquisa Opercional.

[5] Santos, A. T., Marujo, L. G. (2012), O problema de fluxo multiproduto para alocação de frota heterogênea em ferrovias. Universidade Federal do Rio de Janeiro. Marinha do Brasil.

[6] Shirabayashi, J. V., Yamakami, A., Silva, R. C., Shirabayashi, W. V. I. (2017), Metodologias de soluções para o problema de redes multimodais aplicadas ao tráfego urbano. XLIX Simpósio Brasileiro de Pesquisa Operacional.

[7] Silva, M. P., Marujo, L. G. (2012), Análise de modelo intermodal para escoamento da produção da soja no centro oeste brasileiro. Journal of Transport Literature Vol. 6, n. 3, pp. 90-106, Jul 2012.

[8] SteadieSeifi, M., Dellaert, N. P., Nuijten, W., Van Woensel, T., Raoufi, R., (2013), Multimodal freight transportation planning: A literature review. European Journal of Operational Research. Elsevier.

\section{APÊNDICE I}

\section{I.1. CUSTO DE PRODUÇÃO NA PLANTA/ORIGEM $p$ DO PRODUTO $i$ NO PERÍODO $t$ EM HORAS NORMAIS DE PRODUÇÃO $\left(a_{p i t}\right)$}

Tabela I-1: Custos de produção em horas normais dos 2 produtos em 4 períodos de tempo na planta/origem 1

\begin{tabular}{|c|c|c|c|}
\hline Produtos & Períodos & Valores & Unidades \\
\hline \multirow{4}{*}{ Produto 1} & Período 1 & 10,00 & $\mathrm{R} \$$ \\
\hline & Período 2 & 10,50 & $\mathrm{R} \$$ \\
\hline & Período 3 & 10,70 & $\mathrm{R} \$$ \\
\hline & Período 4 & 10,20 & $\mathrm{R} \$$ \\
\hline \multirow{4}{*}{ Produto 2} & Período 1 & 11,50 & $\mathrm{R} \$$ \\
\hline & Período 2 & 10,50 & $\mathrm{R} \$$ \\
\hline & Período 3 & 10,20 & $\mathrm{R} \$$ \\
\hline & Período 4 & 11,00 & $\mathrm{R} \$$ \\
\hline
\end{tabular}

Tabela I-2: Custos de produção em horas normais dos 2 produtos em 4 períodos de tempo na planta/origem 2

\begin{tabular}{c|c|c|c}
\hline \multicolumn{3}{c}{ Planta/Origem 2 - Custos de produção em horas normais } \\
\hline Produtos & Períodos & Valores & Unidades \\
\hline \multirow{4}{*}{ Produto 1 } & Período 1 & 9,00 & $\mathrm{R} \$$ \\
\cline { 2 - 4 } & Período 2 & 9,50 & $\mathrm{R} \$$ \\
\cline { 2 - 4 } & Período 3 & 9,70 & $\mathrm{R} \$$ \\
\cline { 2 - 4 } & Período 4 & 10,00 & $\mathrm{R} \$$ \\
\hline Produto 2 & Período 1 & 11,00 & $\mathrm{R} \$$ \\
\cline { 2 - 4 } & \multicolumn{3}{|c}{}
\end{tabular}




\begin{tabular}{l|l|l|l}
\hline & Período 2 & 10,00 & $\mathrm{R} \$$ \\
\cline { 2 - 4 } & Período 3 & 10,50 & $\mathrm{R} \$$ \\
\hline Período 4 & 10,00 & $\mathrm{R} \$$ \\
\cline { 2 - 4 }
\end{tabular}

\section{I.2. CUSTO DE PRODUÇÃO NA PLANTA $p$ DO PRODUTO $i$ NO PERÍODO $t$ EM HORAS EXTRAS $\left(b_{p i t}\right)$}

Tabela I-3: Custos de produção em horas extras dos 2 produtos em 4 períodos de tempo na planta/origem 1

\begin{tabular}{c|c|c|c}
\multicolumn{3}{c}{ Planta/Origem 1 } & Custos de produção em horas extras \\
\hline Produtos & Períodos & Valores & Unidades \\
\hline \multirow{4}{*}{ Produto 1 } & Período 1 & 15,00 & $\mathrm{R} \$$ \\
\cline { 2 - 4 } & Período 2 & 15,50 & $\mathrm{R} \$$ \\
\cline { 2 - 4 } & Período 3 & 16,00 & $\mathrm{R} \$$ \\
\cline { 2 - 4 } & Período 4 & 15,00 & $\mathrm{R} \$$ \\
\hline \multirow{4}{*}{ Produto 2 } & Período 1 & 20,00 & $\mathrm{R} \$$ \\
\cline { 2 - 4 } & Período 2 & 19,00 & $\mathrm{R} \$$ \\
\cline { 2 - 4 } & Período 3 & 18,00 & $\mathrm{R} \$$ \\
\cline { 2 - 4 } & Período 4 & 20,00 & $\mathrm{R} \$$ \\
\cline { 2 - 4 }
\end{tabular}

Tabela I-4: Custos de produção em horas extras dos 2 produtos em 4 períodos de tempo na planta/origem 2

\begin{tabular}{|c|c|c|c|}
\hline Produtos & Períodos & Valores & Unidades \\
\hline \multirow{4}{*}{ Produto 1} & Período 1 & 16,00 & $\mathrm{R} \$$ \\
\hline & Período 2 & 17,00 & $\mathrm{R} \$$ \\
\hline & Período 3 & 15,50 & $\mathrm{R} \$$ \\
\hline & Período 4 & 17,00 & $\mathrm{R} \$$ \\
\hline \multirow{4}{*}{ Produto 2} & Período 1 & 15,00 & $\mathrm{R} \$$ \\
\hline & Período 2 & 20,00 & $\mathrm{R} \$$ \\
\hline & Período 3 & 18,00 & $\mathrm{R} \$$ \\
\hline & Período 4 & 19,00 & $\mathrm{R} \$$ \\
\hline
\end{tabular}

\section{I.3. CUSTO DE ESTOCAGEM NA PLANTA $p$ DO PRODUTO $i$ NO PERÍODO t $\left(c_{p i t}\right)$}

Tabela I-5: Custos de estocagem dos 2 produtos em 4 períodos de tempo na planta/origem 1

\begin{tabular}{c|c|c|c}
\hline \multicolumn{4}{c}{ Planta/Origem 1 - Custos de estocagem } \\
\hline Produtos & Períodos & Valores & Unidades \\
\hline \multirow{4}{*}{ Produto 1 } & Período 1 & 0.10 & $\mathrm{R} \$$ \\
\cline { 2 - 4 } & Período 2 & 0.10 & $\mathrm{R} \$$ \\
\cline { 2 - 4 } & Período 3 & 0.20 & $\mathrm{R} \$$ \\
\cline { 2 - 4 } & Período 4 & 0.20 & $\mathrm{R} \$$ \\
\hline \multirow{4}{*}{ Produto 2 } & Período 1 & 0.10 & $\mathrm{R} \$$ \\
\cline { 2 - 4 } & Período 2 & 0.10 & $\mathrm{R} \$$ \\
\cline { 2 - 4 } & Período 3 & 0.10 & $\mathrm{R} \$$ \\
\cline { 2 - 4 } & Período 4 & 0.20 & $\mathrm{R} \$$ \\
\cline { 2 - 4 }
\end{tabular}

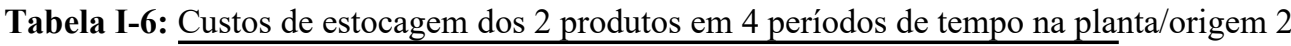

Planta/Origem 2 - Custos de estocagem

\begin{tabular}{c|c|c|c}
\hline Produtos & Períodos & Valores & Unidades \\
\hline \multirow{4}{*}{ Produto 1 } & Período 1 & 0.10 & $\mathrm{R} \$$ \\
\cline { 2 - 4 } & Período 2 & 0.10 & $\mathrm{R} \$$ \\
\cline { 2 - 4 } & Período 3 & 0.10 & $\mathrm{R} \$$ \\
\cline { 2 - 4 } & Período 4 & 0.10 & $\mathrm{R} \$$ \\
\hline \multirow{4}{*}{ Produto 2 } & Período 1 & 0.10 & $\mathrm{R} \$$ \\
\cline { 2 - 4 } & Período 2 & 0.20 & $\mathrm{R} \$$ \\
\cline { 2 - 4 } & Período 3 & 0.20 & $\mathrm{R} \$$ \\
\cline { 2 - 4 } & Período 4 & 0.10 & $\mathrm{R} \$$ \\
\cline { 2 - 4 } & \multicolumn{2}{c}{} &
\end{tabular}




\section{I.4. CAPACIDADE MÁXIMA DE PRODUÇÃO NA PLANTA $p$ DO PRODUTO $i$ NO PERÍODO $t$ EM HORAS NORMAIS DE PRODUÇÃ̃ $\left(d_{p i t}\right)$}

Tabela I-7: Capacidades máximas de produção dos 2 produtos em 4 períodos de tempo na planta/origem 1 em horas normais de produção

\begin{tabular}{c|c|c|c}
\hline Planta/Origem 1 - $\begin{array}{c}\text { Capacidades máximas de produção em ho- } \\
\text { ras normais }\end{array}$ \\
\hline Produtos & Períodos & $\begin{array}{c}\text { Quantida- } \\
\text { de }\end{array}$ & Unidades \\
\hline \multirow{4}{*}{ Produto 1 } & Período 1 & 1000 & Un \\
\cline { 2 - 4 } & Período 2 & 1000 & Un \\
\cline { 2 - 4 } & Período 3 & 1500 & Un \\
\cline { 2 - 4 } & Período 4 & 1500 & Un \\
\hline \multirow{4}{*}{ Produto 2 } & Período 1 & 2000 & Un \\
\cline { 2 - 4 } & Período 2 & 2500 & Un \\
\cline { 2 - 4 } & Período 3 & 3000 & Un \\
\cline { 2 - 4 } & Período 4 & 2500 & Un \\
\cline { 2 - 4 } & \multicolumn{2}{|}{} \\
\hline
\end{tabular}

Tabela I-8: Capacidades máximas de produção dos 2 produtos em 4 períodos de tempo na planta/origem 2 em horas normais de produção

\begin{tabular}{c|c|c|c}
\hline Planta/Origem 2 - Capacidades máximas de produção em ho- \\
ras normais \\
\hline Produtos & Períodos & Quantidade & Unidades \\
\hline \multirow{4}{*}{ Produto 1 } & Período 1 & 2000 & Un \\
\cline { 2 - 4 } & Período 2 & 2500 & Un \\
\cline { 2 - 4 } & Período 3 & 2000 & Un \\
\cline { 2 - 4 } & Período 4 & 1500 & Un \\
\hline \multirow{4}{*}{ Produto 2 } & Período 1 & 1000 & Un \\
\cline { 2 - 4 } & Período 2 & 1500 & Un \\
\cline { 2 - 4 } & Período 3 & 2000 & Un \\
\cline { 2 - 4 } & Período 4 & 3000 & Un \\
\cline { 2 - 4 }
\end{tabular}

\section{I.5. CAPACIDADE MÁXIMA DE PRODUÇÃO NA PLANTA $p$ DO PRODUTO $i$ NO PERÍODO $t$ EM HORAS EXTRAS DE PRODUÇÃO $\left(e_{p i t}\right)$}

Tabela I-9: Capacidades máximas de produção dos 2 produtos em 4 períodos de tempo na planta/origem 1 em horas extras de produção

\begin{tabular}{c|c|c|c}
\hline \multicolumn{3}{c}{ Planta/Origem 1 } & $\begin{array}{c}\text { Capacidades máximas de produção em } \\
\text { horas extras }\end{array}$ \\
\hline Produtos & Períodos & Quantidade & Unidades \\
\hline \multirow{4}{*}{ Produto 1 } & Período 1 & 3000 & Un \\
\cline { 2 - 4 } & Período 2 & 2500 & Un \\
\cline { 2 - 4 } & Período 3 & 2000 & Un \\
\cline { 2 - 4 } & Período 4 & 2500 & Un \\
\hline \multirow{4}{*}{ Produto 2 } & Período 1 & 2500 & Un \\
\cline { 2 - 4 } & Período 2 & 2000 & Un \\
\cline { 2 - 4 } & Período 3 & 3000 & Un \\
\cline { 2 - 4 } & Período 4 & 3000 & Un \\
\cline { 2 - 4 }
\end{tabular}

Tabela I-10: Capacidades máximas de produção dos 2 produtos em 4 períodos de tempo na planta/origem 2 em horas extras de produção

\begin{tabular}{c|c|c|c}
\hline \multicolumn{4}{c}{ Planta/Origem 2 - Capacidades máximas de produção em } \\
horas extras \\
\hline Produtos & Períodos & Quantidade & Unidades \\
\hline \multirow{3}{*}{ Produto 1 } & Período 1 & 4000 & Un \\
\cline { 2 - 4 } & Período 2 & 3500 & Un \\
\cline { 2 - 4 } & Período 3 & 4000 & Un \\
\cline { 2 - 4 }
\end{tabular}




\begin{tabular}{c|c|c|c}
\cline { 2 - 4 } & Período 4 & 2500 & Un \\
\hline \multirow{4}{*}{ Produto 2 } & Período 1 & 1000 & Un \\
\cline { 2 - 4 } & Período 2 & 500 & Un \\
\cline { 2 - 4 } & Período 3 & 2500 & Un \\
\cline { 2 - 4 } & Período 4 & 3000 & Un \\
\hline
\end{tabular}

\section{I.6. CAPACIDADE MÁXIMA DE ESTOCAGEM NA PLANTA p DO PRODUTO i NO PERÍODO t $\left(\mathbf{f}_{\text {pit }}\right)$}

Tabela I-11: Capacidades máximas de estocagem dos 2 produtos em 4 períodos de tempo na planta/origem 1

\begin{tabular}{c|c|c|c}
\hline \multicolumn{3}{c}{ Planta/Origem 1 - Capacidades máximas de estocagem } \\
\hline Produtos & Períodos & Quantidade & Unidades \\
\hline \multirow{4}{*}{ Produto 1 } & Período 1 & 3000 & Un \\
\cline { 2 - 4 } & Período 2 & 3000 & Un \\
\cline { 2 - 4 } & Período 3 & 2000 & $\mathrm{Un}$ \\
\cline { 2 - 4 } & Período 4 & 2000 & $\mathrm{Un}$ \\
\hline \multirow{4}{*}{ Produto 2 } & Período 1 & 2000 & $\mathrm{Un}$ \\
\cline { 2 - 4 } & Período 2 & 2500 & $\mathrm{Un}$ \\
\cline { 2 - 4 } & Período 3 & 2500 & $\mathrm{Un}$ \\
\cline { 2 - 4 } & Período 4 & 3000 & $\mathrm{Un}$ \\
\cline { 2 - 4 }
\end{tabular}

Tabela I-12: Capacidades máximas de estocagem dos 2 produtos em 4 períodos de tempo na planta/origem 2

\begin{tabular}{c|c|c|c}
\hline \multicolumn{3}{c}{ Planta/Origem 2 } & Capacidades máximas de estocagem \\
\hline Produtos & Períodos & Quantidade & Unidades \\
\hline \multirow{4}{*}{ Produto 1 } & Período 1 & 1000 & Un \\
\cline { 2 - 4 } & Período 2 & 1000 & Un \\
\cline { 2 - 4 } & Período 3 & 1200 & Un \\
\cline { 2 - 4 } & Período 4 & 1200 & Un \\
\hline \multirow{4}{*}{ Produto 2 } & Período 1 & 500 & Un \\
\cline { 2 - 4 } & Período 2 & 500 & Un \\
\cline { 2 - 4 } & Período 3 & 700 & Un \\
\cline { 2 - 4 } & Período 4 & 1000 & Un \\
\cline { 2 - 4 }
\end{tabular}

\section{I.7. DEMANDA DO PRODUTO i NO PERÍODO t PELO COMPRADOR j $\left(\mathrm{g}_{\mathrm{itj}}\right)$}

Tabela I-13: Demanda dos 2 produtos em 4 períodos de tempo pelo comprador/destino 1

\begin{tabular}{c|c|c|c}
\hline \multicolumn{4}{c}{ Comprador/Destino 1 - Demandas } \\
\hline Produtos & Períodos & Quantidade & Unidades \\
\hline \multirow{4}{*}{ Produto 1 } & Período 1 & 5000 & Un \\
\cline { 2 - 4 } & Período 2 & 4000 & Un \\
\cline { 2 - 4 } & Período 3 & 3000 & Un \\
\cline { 2 - 4 } & Período 4 & 5000 & Un \\
\hline \multirow{4}{*}{ Produto 2 } & Período 1 & 6000 & Un \\
\cline { 2 - 4 } & Período 2 & 5000 & Un \\
\cline { 2 - 4 } & Período 3 & 200 & Un \\
\cline { 2 - 4 } & Período 4 & 7000 & Un \\
\cline { 2 - 4 } & & \multicolumn{2}{|c}{}
\end{tabular}

Tabela I-14: Demanda dos 2 produtos em 4 períodos de tempo pelo comprador/destino 2

\begin{tabular}{c|c|c|c}
\hline \multicolumn{4}{c}{ Comprador/Destino 2 - Demandas } \\
\hline Produtos & Períodos & Quantidade & Unidades \\
\hline \multirow{4}{*}{ Produto 1 } & Período 1 & 1000 & Un \\
\cline { 2 - 4 } & Período 2 & 2500 & Un \\
\cline { 2 - 4 } & Período 3 & 3000 & Un \\
\cline { 2 - 4 } & Período 4 & 100 & Un \\
\hline \multirow{4}{*}{ Produto 2 } & Período 1 & 100 & Un \\
\cline { 2 - 4 } & Período 2 & 1000 & Un \\
\cline { 2 - 4 } & Período 3 & 1000 & Un \\
\cline { 2 - 4 }
\end{tabular}




\begin{tabular}{|l|l|l|} 
Período 4 & 2000 & Un \\
\hline
\end{tabular}

Tabela I-15: Demanda dos 2 produtos em 4 períodos de tempo pelo comprador/destino 3

\begin{tabular}{c|c|c|c}
\hline \multicolumn{4}{c}{ Comprador/Destino 3 - Demandas } \\
\hline Produtos & Períodos & Quantidade & Unidades \\
\hline \multirow{4}{*}{ Produto 1 } & Período 1 & 100 & Un \\
\cline { 2 - 4 } & Período 2 & 500 & Un \\
\cline { 2 - 4 } & Período 3 & 1000 & Un \\
\cline { 2 - 4 } & Período 4 & 1000 & Un \\
\hline \multirow{4}{*}{ Produto 2 } & Período 1 & 100 & Un \\
\cline { 2 - 4 } & Período 2 & 100 & Un \\
\cline { 2 - 4 } & Período 3 & 200 & Un \\
\cline { 2 - 4 } & Período 4 & 100 & Un \\
\cline { 2 - 4 } & \multicolumn{3}{|c}{}
\end{tabular}

Tabela I-16: Demanda dos 2 produtos em 4 períodos de tempo pelo comprador/destino 4

\begin{tabular}{c|c|c|c}
\hline \multicolumn{4}{c}{ Comprador/Destino 4 - Demandas } \\
\hline Produtos & Períodos & Quantidades & Unidades \\
\hline \multirow{4}{*}{ Produto 1 } & Período 1 & 50 & Un \\
\cline { 2 - 4 } & Período 2 & 100 & Un \\
\cline { 2 - 4 } & Período 3 & 150 & Un \\
\cline { 2 - 4 } & Período 4 & 200 & Un \\
\hline \multirow{4}{*}{ Produto 2 } & Período 1 & 300 & Un \\
\cline { 2 - 4 } & Período 2 & 200 & Un \\
\cline { 2 - 4 } & Período 3 & 100 & Un \\
\cline { 2 - 4 } & Período 4 & 100 & Un \\
\cline { 2 - 4 } & \multicolumn{3}{|c}{}
\end{tabular}

I.8. CUSTO UNITÁRIO DO TRANSPORTE DA PLANTA/ORIGEM p DO PRODUTO i NO PERÍODO T PARA O COMPRADOR/DESTINO j NO MEIO DE TRANSPORTE $m\left(h_{\text {pitjm }}\right)$

Tabela I-17: Custos unitários de transporte entre a planta/origem 1 dos 2 produtos em 4 períodos de tempo para os 4 compradores/destinos nos 3 meios de transporte

\begin{tabular}{|c|c|c|c|c|c|}
\hline \multicolumn{6}{|c|}{ Planta/Origem 1 - Custos unitários de transporte } \\
\hline Produtos & Períodos & Compradores/Destinos & $\begin{array}{l}\text { Meios de Trans- } \\
\text { porte }\end{array}$ & Valores & Unidades \\
\hline \multirow{4}{*}{ Produto 1} & Período 1 & \multirow{4}{*}{ Comprador/Destino 1} & \multirow{4}{*}{$\begin{array}{c}\text { Meio de Transporte } \\
1\end{array}$} & 1,00 & $\mathrm{R} \$$ \\
\hline & Período 2 & & & 0,50 & $\mathrm{R} \$$ \\
\hline & Período 3 & & & 1,50 & $\mathrm{R} \$$ \\
\hline & Período 4 & & & 1,50 & $\mathrm{R} \$$ \\
\hline \multirow{4}{*}{ Produto 2} & Período 1 & \multirow{4}{*}{ Comprador/Destino 1} & \multirow{4}{*}{$\begin{array}{c}\text { Meio de Transporte } \\
1\end{array}$} & 2,00 & $\mathrm{R} \$$ \\
\hline & Período 2 & & & 1,50 & $\mathrm{R} \$$ \\
\hline & Período 3 & & & 1,00 & $\mathrm{R} \$$ \\
\hline & Período 4 & & & 1,50 & $\mathrm{R} \$$ \\
\hline \multirow{4}{*}{ Produto 1} & Período 1 & \multirow{4}{*}{ Comprador/Destino 2} & \multirow{4}{*}{$\begin{array}{c}\text { Meio de Transporte } \\
1\end{array}$} & 1,00 & $\mathrm{R} \$$ \\
\hline & Período 2 & & & 1,50 & $\mathrm{R} \$$ \\
\hline & Período 3 & & & 2,50 & $\mathrm{R} \$$ \\
\hline & Período 4 & & & 3,00 & $\mathrm{R} \$$ \\
\hline \multirow{4}{*}{ Produto 2} & Período 1 & \multirow{4}{*}{ Comprador/Destino 2} & \multirow{4}{*}{$\begin{array}{c}\text { Meio de Transporte } \\
1\end{array}$} & 1,50 & $\mathrm{R} \$$ \\
\hline & Período 2 & & & 1,50 & $\mathrm{R} \$$ \\
\hline & Período 3 & & & 0,50 & $\mathrm{R} \$$ \\
\hline & Período 4 & & & 4,00 & $\mathrm{R} \$$ \\
\hline \multirow{3}{*}{ Produto 1} & Período 1 & \multirow{7}{*}{ Comprador/Destino 3} & \multirow{7}{*}{$\begin{array}{c}\text { Meio de Transporte } \\
1\end{array}$} & 2,00 & $\mathrm{R} \$$ \\
\hline & Período 2 & & & 1,00 & $\mathrm{R} \$$ \\
\hline & Período 3 & & & 2,50 & $\mathrm{R} \$$ \\
\hline \multirow{4}{*}{ Produto 2} & Período 4 & & & 3,50 & $\mathrm{R} \$$ \\
\hline & Período 1 & & & 2,50 & $\mathrm{R} \$$ \\
\hline & Período 2 & & & 2,00 & $\mathrm{R} \$$ \\
\hline & Período 3 & & & 2,00 & $\mathrm{R} \$$ \\
\hline
\end{tabular}




\begin{tabular}{|c|c|c|c|c|c|}
\hline & Período 4 & & & 2,00 & $\mathrm{R} \$$ \\
\hline \multirow{4}{*}{ Produto 1} & Período 1 & \multirow{4}{*}{ Comprador/Destino 4} & \multirow{4}{*}{$\begin{array}{c}\text { Meio de Transporte } \\
1\end{array}$} & 2,50 & $\mathrm{R} \$$ \\
\hline & Período 2 & & & 0,50 & $\mathrm{R} \$$ \\
\hline & Período 3 & & & 1,50 & $\mathrm{R} \$$ \\
\hline & Período 4 & & & 2,50 & $\mathrm{R} \$$ \\
\hline \multirow{4}{*}{ Produto 2} & Período 1 & \multirow{4}{*}{ Comprador/Destino 4} & \multirow{4}{*}{$\begin{array}{c}\text { Meio de Transporte } \\
1\end{array}$} & 3,00 & $\mathrm{R} \$$ \\
\hline & Período 2 & & & 1,50 & $\mathrm{R} \$$ \\
\hline & Período 3 & & & 0,50 & $\mathrm{R} \$$ \\
\hline & Período 4 & & & 0,50 & $\mathrm{R} \$$ \\
\hline \multirow{4}{*}{ Produto 1} & Período 1 & \multirow{4}{*}{ Comprador/Destino 1} & \multirow{4}{*}{$\begin{array}{c}\text { Meio de Transporte } \\
2\end{array}$} & 2,00 & $\mathrm{R} \$$ \\
\hline & Período 2 & & & 2,00 & $\mathrm{R} \$$ \\
\hline & Período 3 & & & 1,00 & $\mathrm{R} \$$ \\
\hline & Período 4 & & & 2,00 & $\mathrm{R} \$$ \\
\hline \multirow{4}{*}{ Produto 2} & Período 1 & \multirow{4}{*}{ Comprador/Destino 1} & \multirow{4}{*}{$\begin{array}{c}\text { Meio de Transporte } \\
2\end{array}$} & 3,00 & $\mathrm{R} \$$ \\
\hline & Período 2 & & & 2,00 & $\mathrm{R} \$$ \\
\hline & Período 3 & & & 2,50 & $\mathrm{R} \$$ \\
\hline & Período 4 & & & 1,00 & $\mathrm{R} \$$ \\
\hline \multirow{4}{*}{ Produto 1} & Período 1 & \multirow{4}{*}{ Comprador/Destino 2} & \multirow{4}{*}{$\begin{array}{c}\text { Meio de Transporte } \\
2\end{array}$} & 2,00 & $\mathrm{R} \$$ \\
\hline & Período 2 & & & 3,00 & $\mathrm{R} \$$ \\
\hline & Período 3 & & & 2,00 & $\mathrm{R} \$$ \\
\hline & Período 4 & & & 1,00 & $\mathrm{R} \$$ \\
\hline \multirow{4}{*}{ Produto 2} & Período 1 & \multirow{4}{*}{ Comprador/Destino 2} & \multirow{4}{*}{$\begin{array}{c}\text { Meio de Transporte } \\
2\end{array}$} & 2,00 & $\mathrm{R} \$$ \\
\hline & Período 2 & & & 2,00 & $\mathrm{R} \$$ \\
\hline & Período 3 & & & 2,00 & $\mathrm{R} \$$ \\
\hline & Período 4 & & & 3,00 & $\mathrm{R} \$$ \\
\hline & Período 1 & & & 3,50 & $\mathrm{R} \$$ \\
\hline & Período 2 & & Meio de Transporte & 3,00 & $\mathrm{R} \$$ \\
\hline Produto 1 & Período 3 & Comprador/Destino 3 & 2 & 3,00 & $\mathrm{R} \$$ \\
\hline & Período 4 & & & 4,00 & $\mathrm{R} \$$ \\
\hline & Período 1 & & & 2,00 & $\mathrm{R} \$$ \\
\hline & Período 2 & & Meio de Transporte & 1,50 & $\mathrm{R} \$$ \\
\hline Produto 2 & Período 3 & Comprador/Destino 3 & 2 & 0,50 & $\mathrm{R} \$$ \\
\hline & Período 4 & & & 3,50 & $\mathrm{R} \$$ \\
\hline & Período 1 & & & 1,50 & $\mathrm{R} \$$ \\
\hline Droduto 1 & Período 2 & Comprodor/Dostine & Meio de Transporte & 1,00 & $\mathrm{R} \$$ \\
\hline Produto I & Período 3 & Comprador/Destino 4 & 2 & 1,00 & $\mathrm{R} \$$ \\
\hline & Período 4 & & & 3,00 & $\mathrm{R} \$$ \\
\hline & Período 1 & & & 1,50 & $\mathrm{R} \$$ \\
\hline Dreduto 2 & Período 2 & & Meio de Transporte & 2,00 & $\mathrm{R} \$$ \\
\hline Produto 2 & Período 3 & Comprador/Destıno 4 & 2 & 2,00 & $\mathrm{R} \$$ \\
\hline & Período 4 & & & 2,00 & $\mathrm{R} \$$ \\
\hline & Período 1 & & & 3,00 & $\mathrm{R} \$$ \\
\hline & Período 2 & & Meio de Transporte & 1,00 & $\mathrm{R} \$$ \\
\hline Produto 1 & Período 3 & Comprador/Destino I & 3 & 2,00 & $\mathrm{R} \$$ \\
\hline & Período 4 & & & 1,00 & $\mathrm{R} \$$ \\
\hline & Período 1 & & & 1,00 & $\mathrm{R} \$$ \\
\hline Produto? & Período 2 & Comnrador/Dectine 1 & Meio de Transporte & 1,00 & $\mathrm{R} \$$ \\
\hline Produto 2 & Período 3 & Comprador/Destino I & 3 & 2,00 & $\mathrm{R} \$$ \\
\hline & Período 4 & & & 2,00 & $\mathrm{R} \$$ \\
\hline & Período 1 & & & 1,50 & $\mathrm{R} \$$ \\
\hline & Período 2 & & Meio de Transporte & 1,00 & $\mathrm{R} \$$ \\
\hline Produto I & Período 3 & Comprador/Destino 2 & 3 & 2,00 & $\mathrm{R} \$$ \\
\hline & Período 4 & & & 2,00 & $\mathrm{R} \$$ \\
\hline & Período 1 & & & 1,00 & $\mathrm{R} \$$ \\
\hline & Período 2 & & Meio de Transporte & 1,00 & $\mathrm{R} \$$ \\
\hline Produto 2 & Período 3 & Comprador/Destino 2 & 3 & 1,00 & $\mathrm{R} \$$ \\
\hline & Período 4 & & & 1,00 & $\mathrm{R} \$$ \\
\hline
\end{tabular}




\begin{tabular}{|c|c|c|c|c|c|}
\hline \multirow{4}{*}{ Produto 1} & Período 1 & \multirow{4}{*}{ Comprador/Destino 3} & \multirow{4}{*}{$\begin{array}{c}\text { Meio de Transporte } \\
3\end{array}$} & 3,00 & $\mathrm{R} \$$ \\
\hline & Período 2 & & & 4,00 & $\mathrm{RS}$ \\
\hline & Período 3 & & & 2,00 & $\mathrm{R} \$$ \\
\hline & Período 4 & & & 3,00 & $\mathrm{R} \$$ \\
\hline \multirow{4}{*}{ Produto 2} & Período 1 & \multirow{4}{*}{ Comprador/Destino 3} & \multirow{4}{*}{$\begin{array}{c}\text { Meio de Transporte } \\
3\end{array}$} & 1,00 & $\mathrm{RS}$ \\
\hline & Período 2 & & & 1,00 & $\mathrm{R} \$$ \\
\hline & Período 3 & & & 1,00 & $\mathrm{R} \$$ \\
\hline & Período 4 & & & 3,00 & $\mathrm{R} \$$ \\
\hline \multirow{4}{*}{ Produto 1} & Período 1 & \multirow{4}{*}{ Comprador/Destino 4} & \multirow{4}{*}{$\begin{array}{c}\text { Meio de Transporte } \\
3\end{array}$} & 1,00 & $\mathrm{R} \$$ \\
\hline & Período 2 & & & 2,00 & $\mathrm{R} \$$ \\
\hline & Período 3 & & & 2,00 & $\mathrm{R} \$$ \\
\hline & Período 4 & & & 2,00 & $\mathrm{R} \$$ \\
\hline \multirow{4}{*}{ Produto 2} & Período 1 & \multirow{4}{*}{ Comprador/Destino 4} & \multirow{4}{*}{$\begin{array}{c}\text { Meio de Transporte } \\
3\end{array}$} & 1,00 & $\mathrm{R} \$$ \\
\hline & Período 2 & & & 1,00 & $\mathrm{R} \$$ \\
\hline & Período 3 & & & 1,00 & $\mathrm{R} \$$ \\
\hline & Período 4 & & & 1,00 & $\mathrm{R} \$$ \\
\hline
\end{tabular}

Tabela I-18: Custos unitários de transporte entre a planta/origem 2 dos 2 produtos em 4 períodos de tempo para os 4 compradores/destinos nos 3 meios de transporte

\begin{tabular}{|c|c|c|c|c|c|}
\hline \multicolumn{6}{|c|}{ Planta/Origem 2 - Custos unitários de transporte } \\
\hline Produtos & Períodos & Compradores/Destinos & $\begin{array}{c}\text { Meios de Transpor- } \\
\text { te }\end{array}$ & Valores & Unidades \\
\hline \multirow{4}{*}{ Produto 1} & Período 1 & \multirow{4}{*}{ Comprador/Destino 1} & \multirow{4}{*}{$\begin{array}{c}\text { Meio de Transporte } \\
1\end{array}$} & 5,00 & $\mathrm{R} \$$ \\
\hline & Período 2 & & & 3,00 & $\mathrm{R} \$$ \\
\hline & Período 3 & & & 3,00 & $\mathrm{R} \$$ \\
\hline & Período 4 & & & 3,50 & $\mathrm{R} \$$ \\
\hline \multirow{4}{*}{ Produto 2} & Período 1 & \multirow{4}{*}{ Comprador/Destino 1} & \multirow{4}{*}{$\begin{array}{c}\text { Meio de Transporte } \\
1\end{array}$} & 4,00 & $\mathrm{R} \$$ \\
\hline & Período 2 & & & 3,00 & $\mathrm{R} \$$ \\
\hline & Período 3 & & & 3,00 & $\mathrm{R} \$$ \\
\hline & Período 4 & & & 1,00 & $\mathrm{R} \$$ \\
\hline \multirow{4}{*}{ Produto 1} & Período 1 & \multirow{4}{*}{ Comprador/Destino 2} & \multirow{4}{*}{$\begin{array}{c}\text { Meio de Transporte } \\
1\end{array}$} & 4,00 & $\mathrm{R} \$$ \\
\hline & Período 2 & & & 3,00 & $\mathrm{R} \$$ \\
\hline & Período 3 & & & 2,00 & $\mathrm{R} \$$ \\
\hline & Período 4 & & & 2,00 & $\mathrm{R} \$$ \\
\hline \multirow{4}{*}{ Produto 2} & Período 1 & \multirow{4}{*}{ Comprador/Destino 2} & \multirow{4}{*}{$\begin{array}{c}\text { Meio de Transporte } \\
1\end{array}$} & 1,00 & $\mathrm{R} \$$ \\
\hline & Período 2 & & & 2,50 & $\mathrm{RS}$ \\
\hline & Período 3 & & & 3,00 & $\mathrm{R} \$$ \\
\hline & Período 4 & & & 2,50 & $\mathrm{R} \$$ \\
\hline \multirow{4}{*}{ Produto 1} & Período 1 & \multirow{8}{*}{ Comprador/Destino 3} & \multirow{8}{*}{$\begin{array}{c}\text { Meio de Transporte } \\
1\end{array}$} & 1,00 & $\mathrm{R} \$$ \\
\hline & Período 2 & & & 5,00 & $\mathrm{R} \$$ \\
\hline & Período 3 & & & 2,00 & $\mathrm{R} \$$ \\
\hline & Período 4 & & & 1,00 & $\mathrm{R} \$$ \\
\hline \multirow{4}{*}{ Produto 2} & Período 1 & & & 3,00 & $\mathrm{R} \$$ \\
\hline & Período 2 & & & 3,00 & $\mathrm{R} \$$ \\
\hline & Período 3 & & & 1,00 & $\mathrm{R} \$$ \\
\hline & Período 4 & & & 3,00 & $\mathrm{R} \$$ \\
\hline \multirow{4}{*}{ Produto 1} & Período 1 & \multirow{4}{*}{ Comprador/Destino 4} & \multirow{4}{*}{$\begin{array}{c}\text { Meio de Transporte } \\
1\end{array}$} & 6,00 & $\mathrm{R} \$$ \\
\hline & Período 2 & & & 5,00 & $\mathrm{R} \$$ \\
\hline & Período 3 & & & 5,00 & $\mathrm{R} \$$ \\
\hline & Período 4 & & & 5,00 & $\mathrm{R} \$$ \\
\hline \multirow{4}{*}{ Produto 2} & Período 1 & \multirow{4}{*}{ Comprador/Destino 4} & \multirow{4}{*}{$\begin{array}{c}\text { Meio de Transporte } \\
1\end{array}$} & 2,00 & $\mathrm{R} \$$ \\
\hline & Período 2 & & & 3,00 & $\mathrm{R} \$$ \\
\hline & Período 3 & & & 2,00 & $\mathrm{R} \$$ \\
\hline & Período 4 & & & 3,00 & $\mathrm{R} \$$ \\
\hline \multirow[t]{3}{*}{ Produto 1} & Período 1 & \multirow[t]{3}{*}{ Comprador/Destino 1} & \multirow{3}{*}{$\begin{array}{c}\text { Meio de Transporte } \\
2\end{array}$} & 4,00 & $\mathrm{R} \$$ \\
\hline & Período 2 & & & 4,00 & $\mathrm{R} \$$ \\
\hline & Período 3 & & & 2,00 & $\mathrm{R} \$$ \\
\hline
\end{tabular}




\begin{tabular}{|c|c|c|c|c|c|}
\hline & Período 4 & & & 3,00 & $\mathrm{R} \$$ \\
\hline \multirow{4}{*}{ Produto 2} & Período 1 & \multirow{4}{*}{ Comprador/Destino 1} & \multirow{4}{*}{$\begin{array}{c}\text { Meio de Transporte } \\
2\end{array}$} & 1,00 & $\mathrm{R} \$$ \\
\hline & Período 2 & & & 1,00 & $\mathrm{R} \$$ \\
\hline & Período 3 & & & 1,50 & $\mathrm{R} \$$ \\
\hline & Período 4 & & & 1,50 & $\mathrm{R} \$$ \\
\hline \multirow{4}{*}{ Produto 1} & Período 1 & \multirow{4}{*}{ Comprador/Destino 2} & \multirow{4}{*}{$\begin{array}{c}\text { Meio de Transporte } \\
2\end{array}$} & 5,00 & $\mathrm{R} \$$ \\
\hline & Período 2 & & & 5,00 & $\mathrm{R} \$$ \\
\hline & Período 3 & & & 5,00 & $\mathrm{R} \$$ \\
\hline & Período 4 & & & 4,00 & $\mathrm{R} \$$ \\
\hline \multirow{4}{*}{ Produto 2} & Período 1 & \multirow{4}{*}{ Comprador/Destino 2} & \multirow{4}{*}{$\begin{array}{c}\text { Meio de Transporte } \\
2\end{array}$} & 4,00 & $\mathrm{RS}$ \\
\hline & Período 2 & & & 3,00 & $\mathrm{R} \$$ \\
\hline & Período 3 & & & 2,00 & $\mathrm{R} \$$ \\
\hline & Período 4 & & & 4,00 & $\mathrm{R} \$$ \\
\hline \multirow{4}{*}{ Produto 1} & Período 1 & \multirow{4}{*}{ Comprador/Destino 3} & \multirow{4}{*}{$\begin{array}{c}\text { Meio de Transporte } \\
2\end{array}$} & 2,50 & $\mathrm{R} \$$ \\
\hline & Período 2 & & & 2,50 & $\mathrm{R} \$$ \\
\hline & Período 3 & & & 0,50 & $\mathrm{RS}$ \\
\hline & Período 4 & & & 3,50 & $\mathrm{R} \$$ \\
\hline \multirow{4}{*}{ Produto 2} & Período 1 & \multirow{4}{*}{ Comprador/Destino 3} & \multirow{4}{*}{$\begin{array}{c}\text { Meio de Transporte } \\
2\end{array}$} & 4,00 & $\mathrm{R} \$$ \\
\hline & Período 2 & & & 4,00 & $\mathrm{R} \$$ \\
\hline & Período 3 & & & 2,00 & $\mathrm{R} \$$ \\
\hline & Período 4 & & & 1,00 & $\mathrm{R} \$$ \\
\hline \multirow{4}{*}{ Produto 1} & Período 1 & \multirow{4}{*}{ Comprador/Destino 4} & \multirow{4}{*}{$\begin{array}{c}\text { Meio de Transporte } \\
2\end{array}$} & 3,00 & $\mathrm{RS}$ \\
\hline & Período 2 & & & 2,00 & $\mathrm{R} \$$ \\
\hline & Período 3 & & & 3,00 & $\mathrm{R} \$$ \\
\hline & Período 4 & & & 4,00 & $\mathrm{R} \$$ \\
\hline & Período 1 & & & 3,50 & $\mathrm{R} \$$ \\
\hline & Período 2 & & Meio de Transporte & 0,50 & $\mathrm{R} \$$ \\
\hline Produto 2 & Período 3 & Comprador/Destino 4 & 2 & 0,50 & $\mathrm{RS}$ \\
\hline & Período 4 & & & 1,00 & $\mathrm{R} \$$ \\
\hline & Período 1 & & & 3,00 & $\mathrm{R} \$$ \\
\hline & Período 2 & & Meio de Transporte & 2,00 & $\mathrm{R} \$$ \\
\hline Produto 1 & Período 3 & Comprador/Destıno 1 & 3 & 1,00 & $\mathrm{R} \$$ \\
\hline & Período 4 & & & 1,00 & $\mathrm{R} \$$ \\
\hline & Período 1 & & & 3,00 & $\mathrm{R} \$$ \\
\hline Produta? & Período 2 & Comnrador/Dectino 1 & Meio de Transporte & 2,00 & $\mathrm{R} \$$ \\
\hline Produto 2 & Período 3 & Comprador/Destıno 1 & 3 & 1,00 & $\mathrm{R} \$$ \\
\hline & Período 4 & & & 2,00 & $\mathrm{R} \$$ \\
\hline & Período 1 & & & 3,00 & $\mathrm{R} \$$ \\
\hline Drod lo 1 & Período 2 & & Meio de Transporte & 2,00 & $\mathrm{R} \$$ \\
\hline Produto 1 & Período 3 & Comprador/Destino 2 & 3 & 1,00 & $\mathrm{R} \$$ \\
\hline & Período 4 & & & 1,00 & $\mathrm{R} \$$ \\
\hline & Período 1 & & & 3,00 & $\mathrm{R} \$$ \\
\hline Dus la 2 & Período 2 & 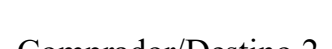 & Meio de Transporte & 2,00 & $\mathrm{R} \$$ \\
\hline Produto 2 & Período 3 & Comprador/Destino 2 & 3 & 1,00 & $\mathrm{R} \$$ \\
\hline & Período 4 & & & 3,00 & $\mathrm{R} \$$ \\
\hline & Período 1 & & & 2,00 & $\mathrm{R} \$$ \\
\hline Droduto 1 & Período 2 & Comprodor/Decting 3 & Meio de Transporte & 2,00 & $\mathrm{R} \$$ \\
\hline Produto 1 & Período 3 & Comprador/Destıno 3 & 3 & 1,00 & $\mathrm{R} \$$ \\
\hline & Período 4 & & & 3,00 & $\mathrm{R} \$$ \\
\hline & Período 1 & & & 2,00 & $\mathrm{R} \$$ \\
\hline & Período 2 & & Meio de Transporte & 2,00 & $\mathrm{R} \$$ \\
\hline Produto 2 & Período 3 & Comprador/Destıno 3 & 3 & 3,00 & $\mathrm{R} \$$ \\
\hline & Período 4 & & & 2,00 & $\mathrm{R} \$$ \\
\hline & Período 1 & & & 2,00 & $\mathrm{R} \$$ \\
\hline Dnola 1 & Período 2 & 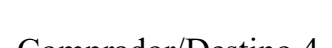 & Meio de Transporte & 3,00 & $\mathrm{R} \$$ \\
\hline Produto 1 & Período 3 & Comprador/Destıno 4 & 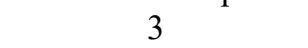 & 1,00 & $\mathrm{R} \$$ \\
\hline & Período 4 & & & 2,00 & $\mathrm{R} \$$ \\
\hline
\end{tabular}




\begin{tabular}{|c|c|c|c|c|c|}
\hline \multirow{4}{*}{ Produto 2} & Período 1 & \multirow{4}{*}{ Comprador/Destino 4} & \multirow{4}{*}{$\begin{array}{c}\text { Meio de Transporte } \\
3\end{array}$} & 3,00 & $\mathrm{RS}$ \\
\hline & \multirow{3}{*}{$\begin{array}{l}\text { Período } 2 \\
\text { Período } 3 \\
\end{array}$} & & & 2,00 & $\mathrm{R} \$$ \\
\hline & & & & 1,00 & $\mathrm{R} \$$ \\
\hline & & & & 4,00 & $\mathrm{R} \$$ \\
\hline
\end{tabular}

